\section{Asymptomatic thoracic aortic aneurysm in a resource limited hospital in a 70-year-old man}

\author{
Mohammad A. Suwaid \\ Department of Radiology, Bayero \\ University, Aminu Kano Teaching \\ Hospital, Kano, Nigeria
}

\begin{abstract}
Aortic aneurysm is a term used to describe more than $50 \%$ dilatation of a segment of the aorta (artery) from its original diameter. The etiological factors include hypertension, artherosclerosis, trauma, congenital syphilis, mycotic bacterial dissection, inflammation etc. A case of a 70-yearold man with well-controlled long-standing hypertension whose check chest X-ray showed aortic aneurysm as an incidental finding which latera ruptured was discussed. The case report discusses the importance of follow up imaging in a hypertensive patient even with regular medication as absence of routine medical checkup including X-ray may lead to missing important complication like aortic aneurysm that can rupture if untreated. This is what prompted this case report so as to underscore the importance of at least check chest radiograph in a hypertensive patient.
\end{abstract}

\section{Introduction}

Aortic aneurysm is a term used to describe more than $50 \%$ dilatation of a segment of the aorta (artery) from its original diameter. ${ }^{1}$ Thoracic aortic aneurysm (TAA) is divided into those involving the ascending aorta, the aortic arch and the descending aorta. $^{2}$ The site of the aneurysm, usually, determines the clinical manifestation, natural history and treatment options. It may also give clues to the aetiology. ${ }^{3}$

TAA is one of the common causes of mediastinal mass. ${ }^{4}$ Normally the diameter of the aorta ranges between $2.4-3.6 \mathrm{~cm}$ from the aortic root to the distal descending aorta. ${ }^{5}$ The mean age for TAA is 65 years with a male to female ratio of $3: 1 .^{3}$ The etiological factors include hypertension, artherosclerosis, trauma, congenital syphilis, mycotic (bacterial) dissection, inflammation (Takayasu arteritis, giant cell arteritis, polychondritis etc), cystic media necrosis in disease like Marfan's syndrome, Ehler's-Danlos syndrome and annuloaortic ectasia). ${ }^{4,6}$

Imaging diagnosis of TAA includes an electrocardiogram, a chest radiograph, an echocardiogram and computed tomography (CT).

Only 1 year survival of $57 \%$ of patients with TAA has been reported. ${ }^{3}$

The importance of follow up imaging in a hypertensive patient even with regular medication and the likely eventual complication of rupture of the aneurysm which occurs in about $42-70 \%$ of patients if left undiagnosed and untreated is what prompted this case report so as to underscore the importance of at least check chest radiograph in a hypertensive patient.

\section{Case Report}

T.J. is a 70-year-old man with well-controlled long-standing hypertension. His physician requested of him a check chest radiograph and shoulder because of complaint of mild shoulder and back pain. His blood pressure was mildly elevated measuring 140/100 $\mathrm{mmHg}$. Heart sound I \& II were heard with early diastolic murmur. All other investigation including laboratory results were normal and this include $\mathrm{FBC}$, Urinalysis, Electrolyte, Urea and Creatinine. Chest radiograph postero-anterior view shows widening of the anterior mediastinum by a smoothly marginated curvilinear soft tissue mass supero-lateral to the heart on the left suggestive of marked unfolding of the aorta (Figure 1). The lateral view shows the affectation of the ascending, the arch and the descending aorta (Figure $2)$. No calcification is however seen. Computed tomography also demonstrated the markedly dilated aorta measuring 7.3 $\mathrm{cm}$ in diameter involving mainly the distal arch and descending aorta but with mild dilatation of the ascending and aortic arch (Figure 3). The patient was referred to University College Hospital Ibadan Nigeria but opted to travel abroad for further investigation and treatment but died soon after before the treatment commenced presumably due to aortic rupture even though post mortem was not done due to religious belief.

\section{Discussion and Conclusions}

The aorta acting as the main conduit through which cardiac output is delivered to the systemic arterial bed is continuously being exposed to high pulsatile pressure and shear stress making it prone to rupture than other vessels particularly with development of aneurysmal dilatation. This is because aortic wall tension is intrinsically high. ${ }^{7}$

This patient presented with very mild
Correspondence: Mohammad A Suwaid, Department of Radiology, Aminu Kano Teaching Hospital, Kano, Nigeria.

Tel.: +234.8033498139.

E-mail: drsuwaid@yahoo.com

Key words: thoracic aortic aneurysm, hypertension, chest X-ray.

Contributions: the authors contributed equally

Conflict of interest: the authors declare no potential conflict of interest.

Funding: none.

Received for publication: 5 August 2018.

Revision received: 10 September 2018.

Accepted for publication: 11 September 2018.

This work is licensed under a Creative Commons Attribution NonCommercial 4.0 License (CC BY-NC 4.0).

(C) Copyright Mohammad A. Suwaid, 2018 Licensee PAGEPress, Italy

Pyramid Journal of Medicine 2018; 1:13 doi:10.4081/pjm.2018.13

symptoms and the attending physicians missed the fact that the patient was in danger of aortic rupture or dissection clinically. Symptoms tend to develop late in the course of aneurysmal dilatation and it usually result from local effects on surrounding structure. ${ }^{5}$ Patients symptoms are generally mild just like in this case. Some cases may present with substernal pain, back and shoulder pain, superior vena cava compression syndrome, dysphagia due to esophageal compression syndrome, stridor, dyspnea due to tracheobronchial compression, hoarseness of breath from compression of the recurrent laryngeal nerve. ${ }^{3}$ This patients' condition was detected because the patient presented with shoulder pain which the attending physician felt was nothing serious, but advised a check X-ray as the normal routine follow up investigation. Detection of the aneurysm usually occurs during investigation due to unrelated reason or as part of screening for certain familial case like Marfan's sundrome. ${ }^{8}$

The chest X-ray for this patient revealed marked aortic unfolding Ascending aortic aneurysm may cause aortic valvular regurgitation leading to congestive cardiac failure, while enlargement of the sinus of vasalva may cause myocardial ischemia leading to infarction. Thromboembolism may also occur. Ascending aortic aneurysm may also rupture directly into right ventricular cavity, right atrium or pulmonary artery leading to heart failure. In fact, rupture of aneurysm is the most common cause of death with rate 
ranging from $42-70 \% .{ }^{9}$ The size of an aneurysm is an important factor in risk of rupture which usually progresses once the diameter reaches $6 \mathrm{~cm}$ or greater with an average rate of increase per annum being $0.2-0.4 \mathrm{~cm}^{3}$

Check chest radiograph for patients with aortic aneurysm is very important as that is what leads to the diagnosis in this case. Chest radiograph is frequently the first test to suggest the diagnosis in asymptomatic patients. However, $17 \%$ of patients with aneurysm will have no abnormalities on chest x-ray. ${ }^{1}$ This patient has marked unfolding of the aorta with widening of the mediastinum in antero-posterior radiograph and cardiac enlargement. Some patients may have wide tortuous aorta with a curvilinear peripheral calcificationt. ${ }^{3}$ Disparity in size between the ascending and descending aorta with irregular wavy contour of the dilated parts is normally seen. In other cases, pleural effusion, atelectasis of lower lobe and displacement of the trachea are some of the findings. ${ }^{4}$

Computed tomography is the most widely used non-invasive technique for the diagnosis of thoracic aneurysm. Size, location and presence of thrombus or chronic dissection are CT diagnosis that can help in the management of aneurysm. The CT on this patient shows the length as well as diameter of the aneurysm. In some other cases the origin of the major branch vessel and extension may be determined. ${ }^{10-12}$ Crescentric hyperdense clots within the false lumen may be seen in dissecting aneurysm if there is any. Internally displaced intimal calcification can also be demonstrated. ${ }^{3}$

The managing physician did not request for echocardiography. However, it normally demonstrates pericardial fluid, intimal fluid (in dissection) and aortic insufficiency. ${ }^{3}$

Non-availability of angiography makes further assessment of the aneurysm more difficult for this patient. However, angiocardiography (aortography) makes visualization of the intimal flap possible and its seen as filling defect within opacified aorta in complicated aneurysm that leads to a dissection. Similarly, double barrel aorta may be seen due to opacification of two aortic lumen. Compression of true lumen by false channel is sometimes noted, while in some instances increase in aortic wall thickness is noted. ${ }^{13}$

MR angiography can provide the same information as CT but does not show mural thrombus calcification. It however has advantage in patient with renal insufficiency. Three dimensional images are usually displayed. ${ }^{3}$

Complication of aortic arch aneurysm includes rupture into the mediastinum and pericardium. Others are aortopulmonary fistula and consolidation of lung adjacent to the aneurysm. ${ }^{6}$ The treatment option for aneurysm is mainly surgical especially if more than $5 \mathrm{~cm}$ in caliber and it involves surgical excision and replacement of the aneurismal portion. Medical management is mainly controlling the blood pressure and the heart rate. ${ }^{6}$ About $57 \%$ of patient with aortic aneurysm have 1year survival while $19 \%$ have 5 years survival.

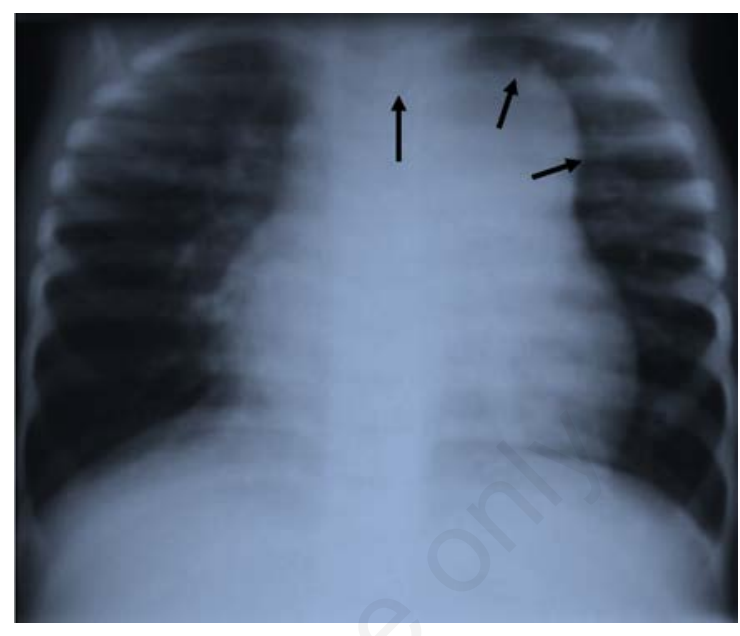

Figure 1. A frontal radiograph showing marked unfolding of the aorta (arrows).

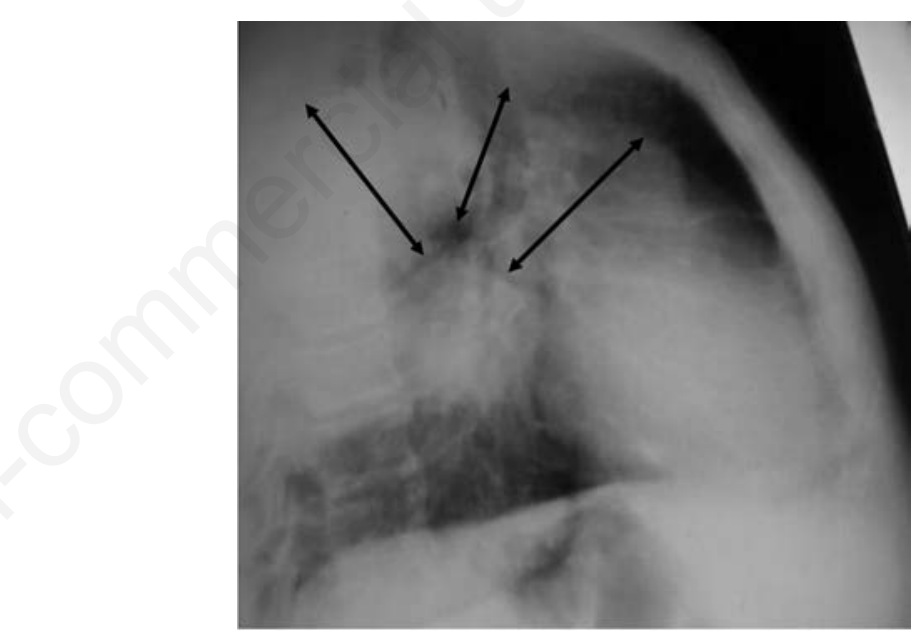

Figure 2. Lateral chest radiograph showing dilatation of the ascending, the arch and the descending aorta (up and down arrow).
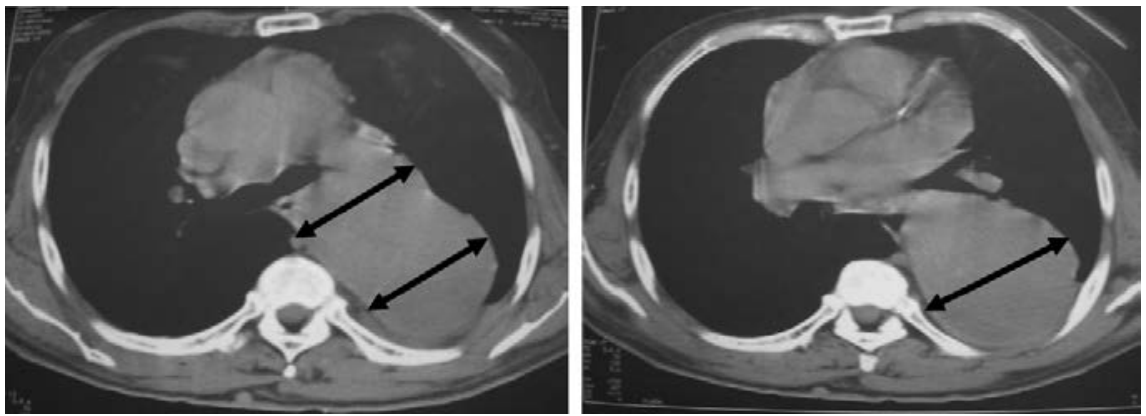

Figure 3. Computed tomography demonstrating the markedly unfolding and dilated aorta (arrows) involving the arch and descending aorta. 


\section{References}

1. Naghibi S, Mirsadrai M. Diagnosis of a Thoracic Aortic Arch Aneurysm in a 63year old Female by CT-Angiography. Int J Radiol. 2007;1528-8404.

2. Coppola R, Bonifazi R, Gucciardo M, Pantaleo P. Ruptured aortic arch aneurysm: transposition of aortic branches after insertion of thoracic endovascular stent with extra-anatomic brain perfusion. Interact Cardiovasc Thorac Surg 2007;6:376-8.

3. Wolfgang D. Urogenital system. In: Radiology review manual. 6th ed. Baltimore: Lippincot Williams and Wilkins; 2002. pp 447-484.

4. Roger HS, Richard WW, Andrew R, et al. Mediastinum. In: Sutton D. Text book of radiology and imaging. 7th ed. London: Churchill Livingstone: 2003. pp 57-76.

5. Hargreaves MR, Gilbert TJ, Pillai R, Hart G. Large airway obstruction by a chronic dissecting aortic aneurysm in the Marfan syndrome. Postgrad Med J 1997;73:726-42.

6. Steckmeier B. Epidemiology of aortic disease: aneurysm, dissection, occlusion. Radiologe 2001;41:624-32.

7. May J, White GH, Waugh $\mathrm{R}$, et al. Endovascular treatment of abdominal aortic aneurysms. Cardiovasc Surg 1999;7:484-90.

8. Crawford ES, Coselli JS, Svensson LG, et al. Diffuse aneurysmal disease (chronic aortic dissection, Marfan, and mega aorta syndromes) and multiple aneurysm. Treatment by subtotal and total aortic replacement emphasising the elephant trunk operation. Ann Surg 1990;21:521-37.

9. Schlosser FJ, Gusberg RJ, Dardik A, et al. Aneurysm rupture after evar: can the ultimate failure be predicted. Eur J Vasc Endovasc Surg 2009;37:15-22.

10. Qanadli SD, Mesurolle B, el Hajjam M. Helical computed tomography of the aorta and its branches. J Radiol 1999;80:998-1010.

11. Willmann JK, Lachat ML, von Smekal A, et al. Spiral-CT angiography to assess feasibility of endovascular aneurysm repair in patients with ruptured aortoiliac aneurysm. Vasa 2001;30:271-6.

12. Imai $Y$, Urayama S, Uyama C. A system for computer-assisted design of stentgrafts for aortic aneurysms using 3-D morphological models. Cardiovasc Intervent Radiol 2001;24:277-9.

13. Farber MA, Criado FJ. Endovascular repair of nontraumatic ruptured thoracic aortic pathologies. Ann Vasc Surg 2005;19:167-71. 